\title{
High Plains Petroglyphs
}

\author{
by A. J. Mruska, Gerald
}

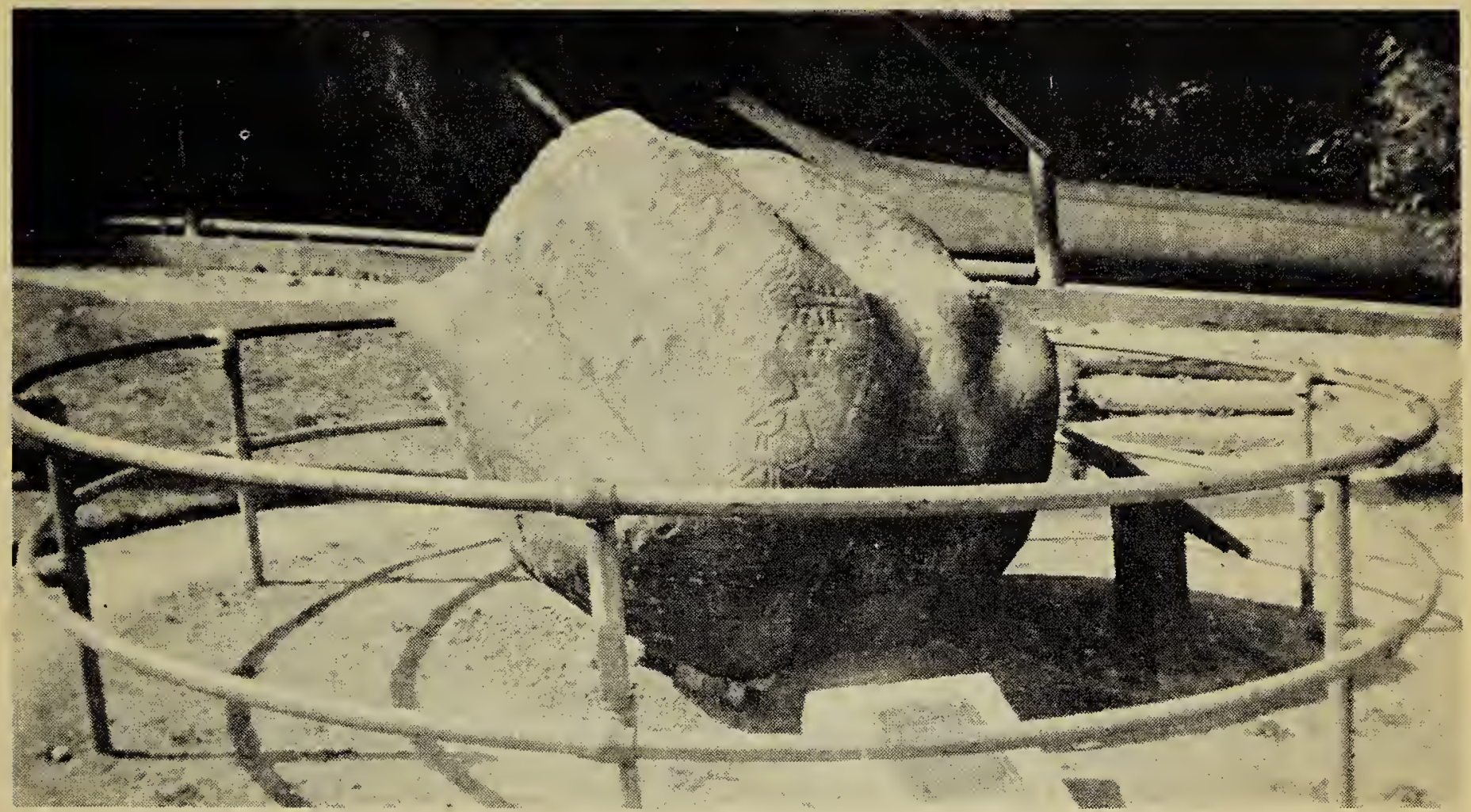

Photo by A. J. Hruska

Fig. 1. Petroglyph in Stanley" Park, Vancouver, brought from fraser River near Lone Creek Cabin, 1926.

There is one aspect of prehistoric Indian culture for which very little information is available - that subject is petroglyphs. This term refers to Indian symbols. or images which are carved or incised on stone, either on boulders or on rock cliffs. Limestone, sandstone and granite are frequently used for this purpose. Petroglyphs are numerous on Vancouver Island but their numbers decrease on the coast mainland. On the inland side of the mountains petroglyphs are found in the foothills and spread out to the high plains. They are also abundant in some regions of Ontario and elsewhere in the east. However, on the prairies their numbers sharply decrease, possibly owing to a lack of suitable materials or perhaps to a lack of this cultural trait. A few have been reported in the past in the Blue Jay - e.g. one found near Tisdale (Blue Jay, 15:169), one found near Weyburn (Blue Jay, 16:42).

An example of a coast petroglyph is shown in figure 1 . This granite boulder is about five feet in diameter and is covered th various small figures and symbcis. Figure 2 shows a high plains petroglyph (see also Blue Jay, 15:43). Though it is larger than the one in figure 1 it is also of granite. Close inspection shows that both bear at least one symbol in common a five-dotted circle.

Some researchers believe that the carvings represent images seen by puberty initiates in religious ceremonies. Others theorize that the dif-

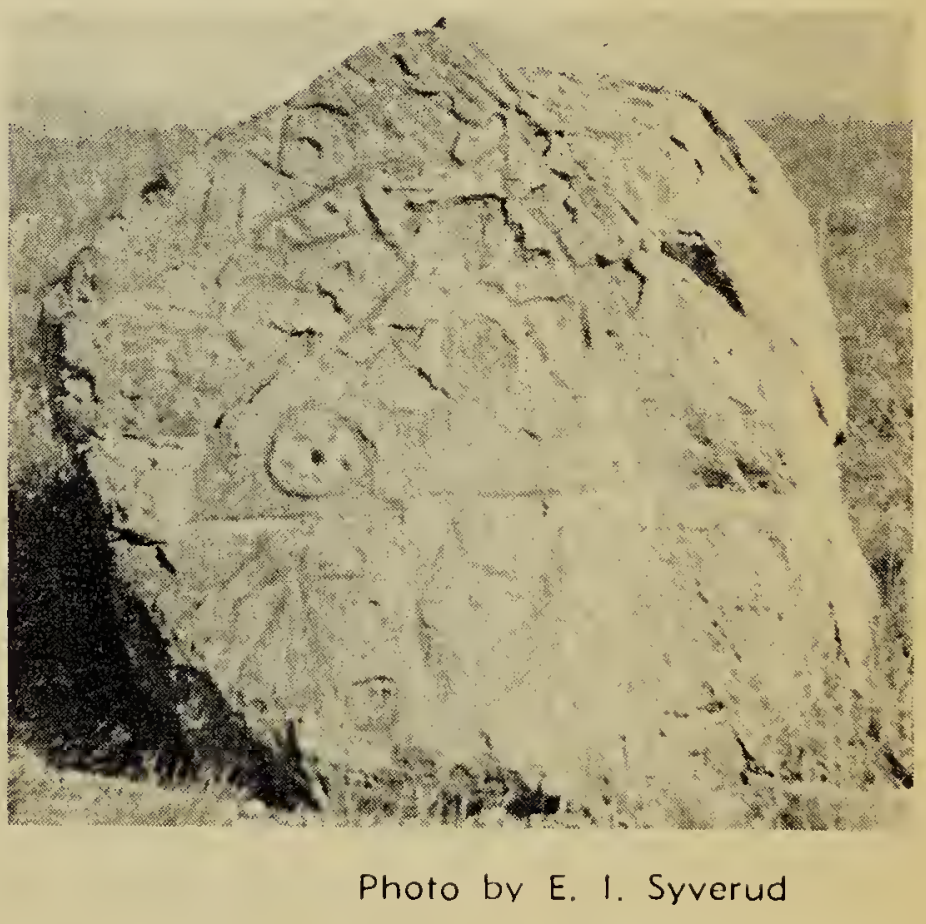

Fig. 2 Petroglyph in Writina Rock State Park, North Dakota, in natural setting. 
ferent symbols represent tribal or chieftain marks. Still others claim that the carvings are marks of tribes passing through the region - a sort of "Kilroy was here" theory. Even though there is little likelihood of our ever attaining full understanding of petroglyphs there is the possibility of tracing the movements of tribes and cultures by a careful study. of all those that remain. Therefore, the observation, reporting, recording, and above all the protection of all petroglyphs is highly desirable.

\section{RED FOX IN GULL LAKE AREA}

\section{by Mrs. J. R. Squires, Admiral}

In the March, 1962 issue of the Blue Jay I read the account by Terry Wedge of a Red Fox sighted in the Gull Lake area. Last August, my husband and I saw a Red Fox in the same area, approximately ten miles south of Gull Lake and a half mile west of Highway No. 37. It crossed the road in front of our car and hid in the ditch which was heavily grown over with sweet clover. When we stopped the car and backed up to watch it, the fox left its hiding place and ran to the field. My husband had seen a Red Fox (possibly the same one?) within a half mile of this place a few weeks earlier and later we spoke to another person who said he had seen one there at about that time.

In the summer of 1960 a Red Fox was killed, presumably by a car, on the Bone Creek Valley road about eight miles west and two miles south of where we saw the fox last August. It was observed by quite a few people at that time. Until reading $\mathrm{Mr}$. Wedge's account I didn't realize that you wanted this information.

\section{KNOW ANY SNAKE PITS ?}

Garter snake hibernacula neededDr. R. Connell of the Veterinary Science Department, University of Saskatchewan, Saskatoon, would like information regarding the location of garter snake hibernacula (dens where garter snakes collect to spend the winter) in Saskatchewan. The Veterinary Science Department is engaged in work aimed at clarifying the role of the garter snake in certain infectious diseases transmissible to livestock and man, Western Equine Encephalomyelitis in particular. Dr. Connell would appreciate hearing from any Blue Jay reader who knows the location of garter snake hibernacula, or who observes considerable numbers of snakes in any spot, in order to collect snakes emerging from hibernacula in the spring.

\section{CECROPIA PUPAE NEEDED FOR RESEARCH}

Saturniid pupae, such as Polyphemus and Cecropia (see Blue Jay, 20: 2833 ), are sought by Dr. Lawrence Gilbert at the Department of Biological Sciences, Northwestern University, Evanston, Illinois. Dr. Gilbert will pay good prices to anyone collecting such pupae for him.

\section{Notes and Letters}

\section{BARRED OWL NESTING SITES}

I was-glad to read in the Blue Jay (19:114-115) that the Barred Owl had finally been found nesting (in a black poplar stub), as I had prophesied when I was at the 1959 meeting of the A.O.U. in Regina.

We do not profess to be expert on the breeding habits of Barred Owls, but we were fortunate enough to find a nest of this species, 15 miles west of Fort William, on May 5, 1940, which contained one egg and a newly-hatched young. On April 6, 1942, we located a second nest about
100 yards from the first tree which had blown down shortly after we had found the nest. This nesting site was again occupied on April 11, 1943. Both years the first sets of eggs were collected, and the female had laid new clutches by May 18, 1942, and May 12, 1943.

Both nests were in cavities near the tops of balsam poplar stubs at elevations of 35 and 30 feet respectively. In no instance were we able to flush the sitting bird by striking the trunk of the tree with a club. In every in- 